\title{
The Impact of High-rise Building Curtain Wall Technology in the Exploring Period (1895-1959)
}

\author{
Ya-Guang SUN ${ }^{1, a, *}$ \\ ${ }^{1}$ Dalian University of Technology School of Architecture \& Fine Art, China \\ aeuro3001@163.com \\ ${ }^{*}$ Corresponding author
}

Keywords: Glass Curtain Wall, High-rise Building, Technology, Aesthetic Features.

\begin{abstract}
This paper is analyzing the impact of Curtain Wall technology for high-rise building style from the views of Curtain Wall technical attributes and history restoring. And it will get the intrinsic link between development of Curtain Wall technology and high-rise building style. Art development was promoted by technology, which art tends to be rational, from technology showing off to ontology of architectural function.
\end{abstract}

\section{Introduction}

In the exploring period of high-rise building, architects would not only use glass as materials of modeling and composition, but also give full play to glass itself characteristics corresponding to the visual and tactile effects, also focus on the artistic temperament by glass material texture performance. Glass has a good visual penetration, this nature changes people's visual experience in building space. It makes no longer isolated from each other between people and environment, makes the building space and natural integrated, meanwhile, through the light elements re-creations, and reaches an ideal environment intention. It creates an illusory beauty from light and color, and brings lightweight, transparent, open aesthetic characteristics to building.

From late of Nineteenth Century to mid of Twentieth Century, Curtain Wall technology had been widely used in the construction area. Due to its light weight, short construction period and the distinctive aesthetics features, it was favored highly by architects and structural engineers. Nowadays, high-rise building Curtain Wall technology was developed, under the impetus of architectural masters; it became a colorful and rich urban landscapes. Meanwhile, though light elements recreation, Curtain Wall technology created an illusory beauty of light and color, which brought the transparent aesthetic characteristics.

Glass was originally a part of window (space organization elements), in 20th century, steel frame structure further developed, so that it made skyscraper and glass curtain wall become the symbol of modern architecture. Frank Wright said:" The external wall is no longer the structural supporting of building. The inner steel frame is real supporting column." The outer wall surface almost disintegrated, left only the pure frame structure to divide the space. From 1851 "Crystal Palace", to New York Lever House, and then to United Nations office building in New York, through large area transparent glass material, showed out the illusory beauty.

\section{Initial Development of Glass Curtain Wall}

In 1890s, Chicago School (Architecture), presented by architect Louis Sullivan and engineer William Le Baron Jenney, marked the rise of high-rise building design. During this period, the technology of large scale flat glass production became popularity. And due to Chicago developed shipping industry, iron and steel, stone and other building materials cost can be reduced. These are objectively caused the vigorous development of Chicago high-rise building. Chicago Reliance Building which built in 1895 is one of the achievements of architectural science and technology at that time. Chicago Reliance Building is designed by architect John Root and Charles Atwood, which 
is the first building in real sense which was made by glass as a whole curtain wall construction. Nearly $70 \%$ façade area was covered by glass and other outer skin parts made of stone and terra-cotta. Due to the glass and steel structure bring lightweight to building, which made the height have a breakthrough, meanwhile, the building style is more selective. The success of Reliance Building has guided the following generations' architects to explore high-rise building design. Even the architect Mies' work in high-rise building, had the effect of Reliance Building.

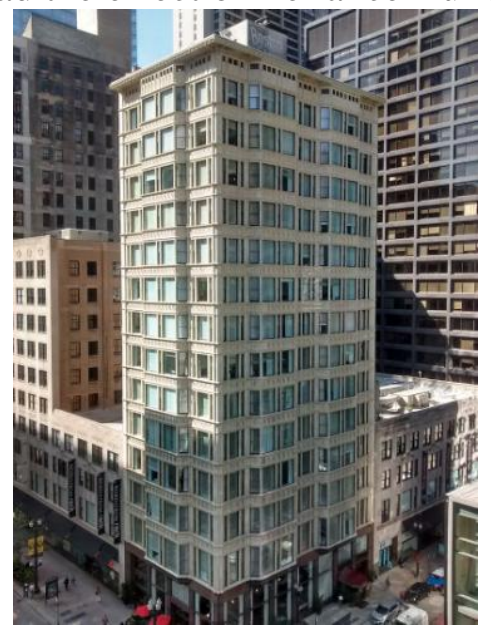

Fig.1 Reliance Building, Chicago, 1895, Resourced by Wikipedia

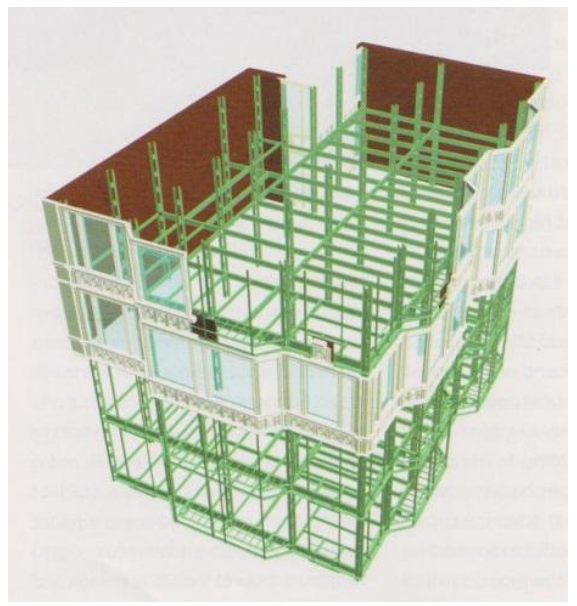

Fig.2 Steel Frame with Curtain Wall, Reliance Building, Resourced by Ryan Risse

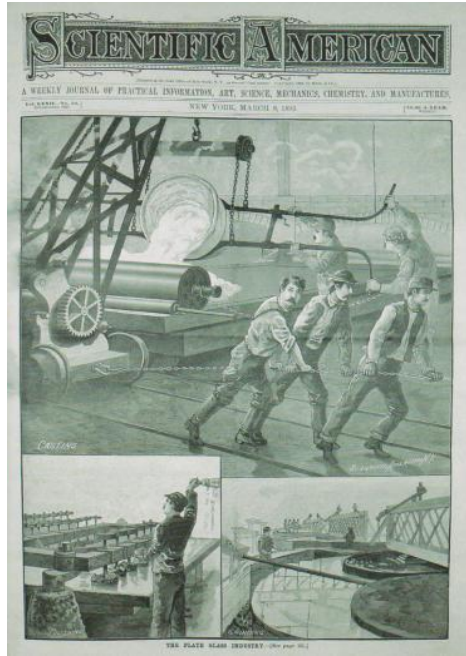

Fig.3 American Mass Production Technology of Flat Glass in $19^{\text {th }}$ Century, Resourced by Scientific American 


\section{High-rise Building in Modernism Context}

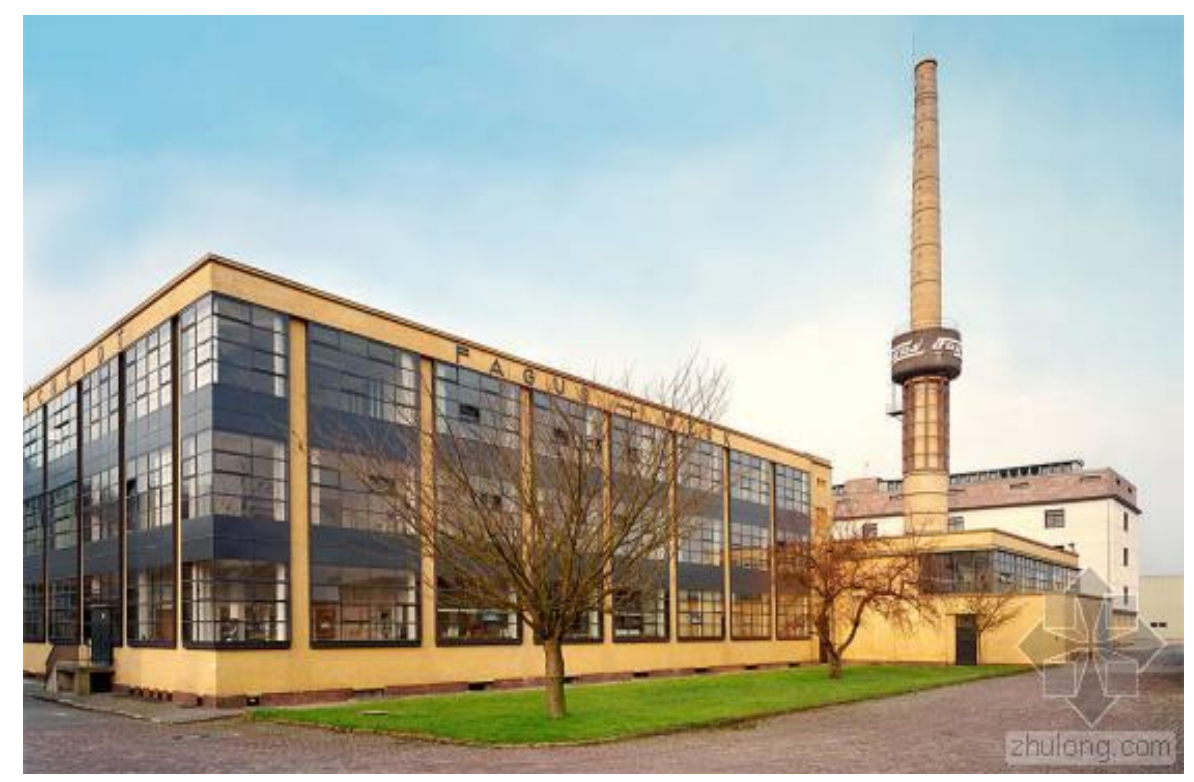

Fig.4 Fagus Factory, Resourced by Zhulong.com

In 1911, Walter Gropius began the attempt in glass curtain wall. He and Adolf Meyer co designed the first European building with glass curtain wall structure, Fagus Factory. That is the first time to use large glass windows and corner windows, separated by thin brick column. It used the method of cantilever to make the overall façade lightweight and weaken the role of pillars in traditional building. Through the glass curtain wall, the building structure became clear.

Gropius used large area glass curtain wall in New Bauhaus School, because of its form is simple and novel, which became one of masterpieces of the New Architectural Style. However, due to the limitations of material conditions, there were many problems in the function. Taking Corbusier's Domino system as the starting point, the building wall was converted into light, and the height was more likely to break through. With the popularization of curtain wall technology, high-rise building appeared in the shape and conception by glass using.

Mies Van der Rohr thought that the glass curtain wall has the reflection function, maps the surrounding scenery, can obtain the rich and colorful artistic effect. In 1919, he designed the concept map of Friedrich Street office building; it has a profound impact on the later development of the building. This is the first full use of glass and steel structure of the high-rise building program, the whole building windows and walls were getting into one, it was not only for the simple form, but also make full use of the advantages of the material. The project pointed out the possibility of future skyscraper, also known as the prototype of contemporary glass curtain wall construction. The program is the first to show Mies's principle of "less is more". But this scheme started from the perspective of shape arts, at that time, the limited technical condition is not in line with the actual. Due to common flat glass in that time, its thermal conductivity is very large. In the large glass curtain wall construction, indoor temperature regulation will be a huge burden.

Mies' frame structure and supporting system, promoted the development of lightweight glass curtain wall. Building envelope used large area glass, instead of the traditional heavy building façade and all kinds of narrow window, which liberated the building façade, made the outdoor landscape get into the interior space that was not limited by shackles of traditional façade design. With the popularization and development of lightweight glass curtain wall, building has the possibility of higher level development. Meanwhile, it also made the comprehensive glass enveloping building emerged, which laid the foundation of theory and technology. 


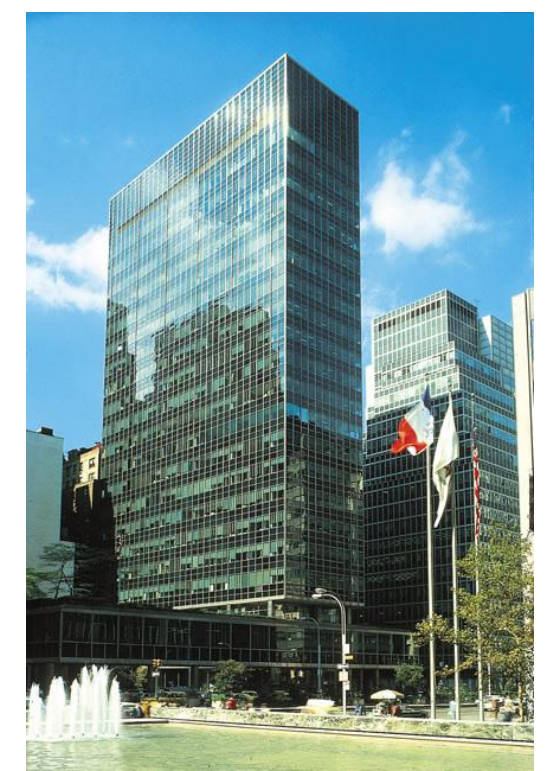

Fig.5 Lever House, New York, Designed by SOM, 1952, Resourced by www.ikuku.cn

In 1959, British Bill Kent Company invented the float glass; large piece flat glass production became possible. From then on, its production technology can be popularized. In this period, stained glass also appeared at 1950s. In the production process, adding different mineral material into raw glass materials, while it will show a different color, blue, bronze, amber mostly. Stained glass' thermal conductivity was same as transparent glass. But with the difference of glass pigment, filtered the corresponding radiation in solar spectrum, it was made shading coefficient be about 0.5. Therefore, stained glass curtain wall could avoid solar exposure in the summer, save using of air conditioning, and avoid glare. In 1950s, the most influence work of high-rise building with glass curtain wall is New York Lever House designed by SOM, and Seagram Building by Mies.

With the change of people's aesthetic psychology, as well as the progress of glass curtain wall technology, glass is no longer the boundaries of indoor and outdoor space. Fuzzy boundaries, made indoor and outdoor space blend. The glass curtain wall is no longer just a transparent envelope on the façade shelter, but the architect's spatial element organizations and light control means. Glass curtain wall also can show the beauty of semi-transparent. According to all transparent and opaque curtain walls, translucent curtain wall stressed the change and imbalance, which can not only block the line of sight and maintain visual contact with clear interface, but also have a hazy image.

The exploration and development of glass curtain wall promotes the space form revolution. Through technical innovation and the use of new materials, it made people understand space more; transparency has become a widespread concern. Technological innovation brings new structural forms, and mechanical mass production of flat glass technology makes the glass curtain wall construction completely universal. Outside and inside become one by transparent glass façade. Architectural object is no longer negative to deal with the surrounding environment, and can re-organize the internal and external space, connectivity or interruption.

\section{Summary}

The development of glass curtain wall has laid a good foundation for the modern architecture characteristics which emphasized function. The modern architecture, which negated past form, taboo decoration, used function beauty as architectural conception. Glass curtain wall has played an effective role in the process of pure non-decorative building construction. The main effect of the functionalism is as followings: Firstly, glass curtain wall can reflect the internal space. In the glass curtain wall building, the role of glass curtain wall is soap bubble, the transparent façade strengthen the performance function of the building internal space. Secondly, the glass curtain wall itself bears the expression function, lighting control, viewing, ventilation, heat preservation, heat insulation, 
noise reduction, interaction of inside and outside, etc., are performance by glass curtain wall. These functions have been given full attention and expressed various forms on the glass curtain wall. These two aspects complement and support each other, and be made one. Glass curtain wall overturned the design method of envelope system in traditional architectural style, so that made architectural design have a certain scientific properties. Therefore, in the term of glass curtain wall technology exploration, people could find a mean to express the rational thinking of modern architecture.

The development of glass curtain wall technology has an inner connection with the influence of high-rise building style. "Technology is a part of human civilization, anti-technology seems to declare war to architecture that civilization itself." With the high speed development of social science and technology, technology is no longer a tool that people transforms nature and creates a better life, but also internalizes into design of cultural connotation and character. It embodies the people's ideal future and attitudes of life, is a distinctive aesthetic orientation of new era. As the tool of recognizing and transforming nature, technology is not only inexhaustible motive force to promote the times progress, or power source of social spiritual culture and orderly development, is factor that architectural art can develop. With the further development of postindustrial society, technology achievements have been greatly improved. People promote the development of arts by technology, while art tends to be rational, from technology showing off to ontology of architectural function.

\section{Acknowledgement}

This research was supported by Dalian University of Technology School of Architecture \& Fine Art.

\section{References}

[1] David Bennett, “Skyscrapers: Form \& Function”, Simon \& Schuster, New York, 1995.

[2] Carl W. Condit, "Chicago, 1910-1929, Building, Planning, and Urban Technology", the University of Chicago Press, Chicago, 1973.

[3] Harry Francis Mallgrave, "Modern Architectural Theory, a Historical Survey, 1673-1968", Cambridge University Press, New York, 2005.

[4] Peter, Jennifer Hyatt. Great Glass Building. Images Publishing Dist A/C, 2006

[5] Ada Louise Huxtable "The Tall Building Artistically Reconsidered: the Search for a Skyscraper Style”, Pantheon Books, New York, 1982.

[6] Thomas Leslie, "Chicago Skyscrapers, 1871-1934”, University of Illinois Press, Urbana, Chicago and Springfield, 2013.

[7] Shouzhi. Wang, History of Modern Architecture, China Architecture \& Building Press, Beijing, China, 1999, 267.

[8] Yide. Dou, Famous Architects ( $2^{\text {nd }}$ Collection), "Norman Foster", China Architecture \& Building Press. Beijing, China, 1997, P-171. 